\title{
GENERATION OF P-Y CURVES FOR LARGE DIAMETER MONOPILES THROUGH NUMERICAL MODELLING
}

\author{
B.Krishnaveni ${ }^{1}$, Satya Kiran Raju Alluri ${ }^{2}$, M.V.Ramana Murthy ${ }^{3}$ \\ ${ }^{I}$ Project Scientist-I, Ocean structures, National Institute of Ocean Technology, Chennai, India \\ ${ }^{2}$ Scientist-C, Ocean structures, National Institute of Ocean Technology, Chennai, India \\ ${ }^{3}$ Scientist-G, Ocean structures, National Institute of Ocean Technology, Chennai, India
}

\begin{abstract}
In recent years, immense requirement for energy all over the world and exploitation of available conventional resources has urged the demand for renewable energy such as wind energy. As large land areas and greater wind speeds are required for increased production the concept of offshore wind farms has come into existence. The complexity in design and higher cost of substructure raises the need for optimization of suitable substructure concept for offshore wind turbine. Among various substructure concepts available for offshore wind turbine, the most suitable one is open ended large diameter (>4m) steel monopile. In monopile design, studying the soil reaction plays a vital role which is usually done through p-y curves. These p-y curves are developed by API which is verified for piles up to $2 \mathrm{~m}$ diameter. As piles used for offshore wind turbine are of greater diameter, Finite element modelling can be developed to account for diameter effects. In this paper, monopiles of shorter and larger diameters are studied through Finite element modelling and compared with the tip deflection generated by conventional API method. Further $p$-y curves are generated for both smaller and larger diameter pile from Finite element modelling, compared and studied with API method of generating p-y curves.
\end{abstract}

Keywords: Offshore wind turbine, Monopile; p-y curves; Pile-Soil interaction; API method; FEM method; Plaxis. $* * *$

\section{INTRODUCTION}

The need for alternative and clean sources of energy is increasing across the world due to increase in energy demand, depletion of fossil fuels and global warming effects [19]. Wind being a pollution free source would be an ideal alternative to meet these demands. At present the focus has shifted to offshore wind to trap higher wind speeds and reduced noise pollution, visual intrusion [19] [13]. However the cost of offshore wind energy is high due to increased cost of substructure including installation [14] [20]. The substructure concepts to support offshore wind turbine includes Gravity foundation, Monopile, Tripod and Jacket [26]. The choice of substructure concept is site specific, soil condition, type of loading, bathymetry profile and availability of construction facilities. Generally, Gravity foundations and monopiles are used for shallow water depths $(10-30 \mathrm{~m})$, Tripods and Jackets for transitional waters $(20-80 \mathrm{~m})$ and floating concepts for very deep waters $(>80 \mathrm{~m})$ [19] are being used. As most of the wind potential sites across the world are in water depths ranging from $10 \mathrm{~m}-$ $25 \mathrm{~m}$, monopiles are widely used as suitable substructure concept [24]. Monopiles are the extension of the tower driven into the soil [21] and have large diameters to resist large lateral forces [11] due to aerodynamic and hydrodynamic loads. The behaviour of wind turbine is majorly governed by pile soil interaction to transfer structural loads to soil. Conventionally, the pile soil interaction is modelled as Winkler's foundation [7] consisting of three orthogonal springs. The stiffness for lateral springs is governed by $p-y$ curves. The stiffness for intermediate layers are governed by the $\mathrm{t}-\mathrm{z}$ curves and end layer is governed by Q-Z curve. The properties for these curves are considered as per API standards [8]. However literature indicates that the API method overestimates the soil stiffness for large diameter piles $(>2 \mathrm{~m})$ [16]. This results in under estimation of the tower tip deflection leading to failure of the turbine under extreme events [12]. In this study a detailed methodology is proposed to generate non-linear lateral stiffness for large diameter piles using Finite Element Modelling. From the Finite Element Modelling results, $\mathrm{p}$-y curves are generated and compared with $\mathrm{p}-\mathrm{y}$ curves obtained from conventional API method.

\section{PILE SOIL INTERACTION-API METHOD}

In case of monopiles, the lateral resistance of the soil in the top layers is significant to the pile design. The pile soil interaction is studied through modelling the pile with three non-linear orthogonal springs considered at regular intervals along the depth of the pile as shown in Fig. 1

The resistance of the soil is modelled as a non-linear spring governed by $\mathrm{p}-\mathrm{y}$ curve at that depth. As per API, for cohesionless soil the $\mathrm{p}-\mathrm{y}$ curve is constructed using stressstrain data from laboratory experiments. The ordinate of these curves is the soil resistance, $p$, and the abscissa is soil deflection, y.

$$
p=A \times p_{u} \times \tanh \left[\frac{k \times H}{A \times \mathrm{pu}_{\mathrm{u}}} \times y\right]
$$

Here ' $k$ ', represents the initial modulus of subgrade reaction which depends on angle of internal friction of soil as shown in Fig. 5. 
The parameter $\mathrm{A}$ is a factor that accounts for cyclic or static loading conditions .

$\mathrm{A}=0.9$ for cyclic loading and $\mathrm{p}_{\mathrm{u}}$ is the maximum sub grade reaction. $\mathrm{p}_{\mathrm{u}}$ is governed by the mode of soil failure which can be either wedge or flow based on the transition depth.

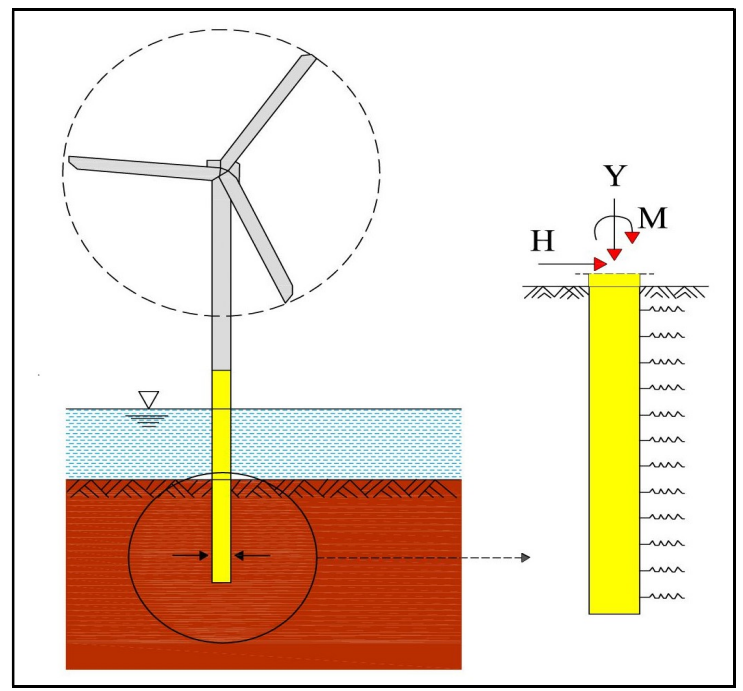

Fig. 1 Pile Soil system

$\mathrm{A}=\left(3.0-\frac{0.8 H}{D}\right)>0.9$ for static loading.

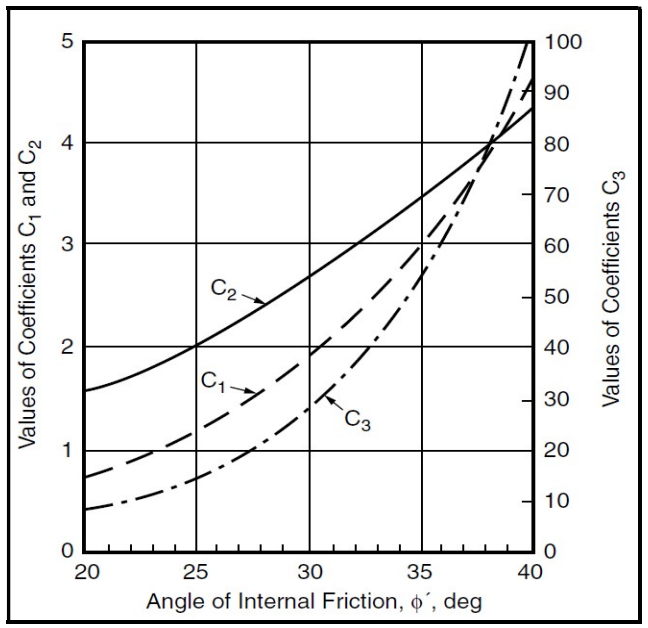

[Reproduced from API RP 2A (2000)]

Fig. 2 Co-efficient C1, C2, C3, based on angle of internal friction

The soil above the transition depth forms a wedge which moves up and out from the pile as shown in Fig. 3 whereas soil below the transition depth flows horizontally around the pile as shown in Fig.4. Considering these two failure mechanisms, the maximum subgrade reaction can be obtained as

$p_{u}=$ minimum of $\left\{\begin{array}{r}\left(C_{1} \cdot z+C_{2} \cdot d\right) \cdot \gamma z \\ \left(C_{3} \cdot d \cdot \gamma z\right)\end{array}\right.$

coefficients $C_{1}, C_{2}$ and $C_{3}$ are functions of the angle of internal friction as shown in Fig. 2 and can be determined according to API(2000).
In the p-y curves the linear part represents the elastic behaviour of the soil beyond which the curve becomes parabolic as the load increases.
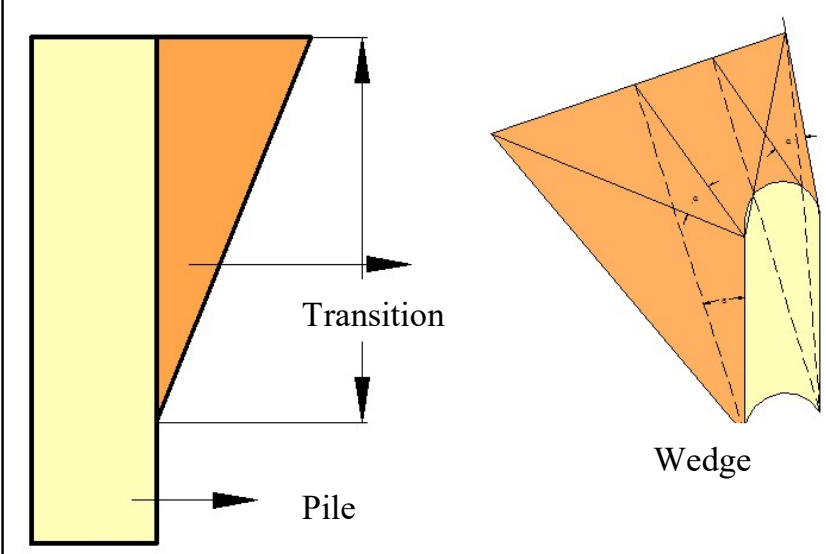

Wedge

Fig. 3 Wedge Failure Mechanism above transition depth

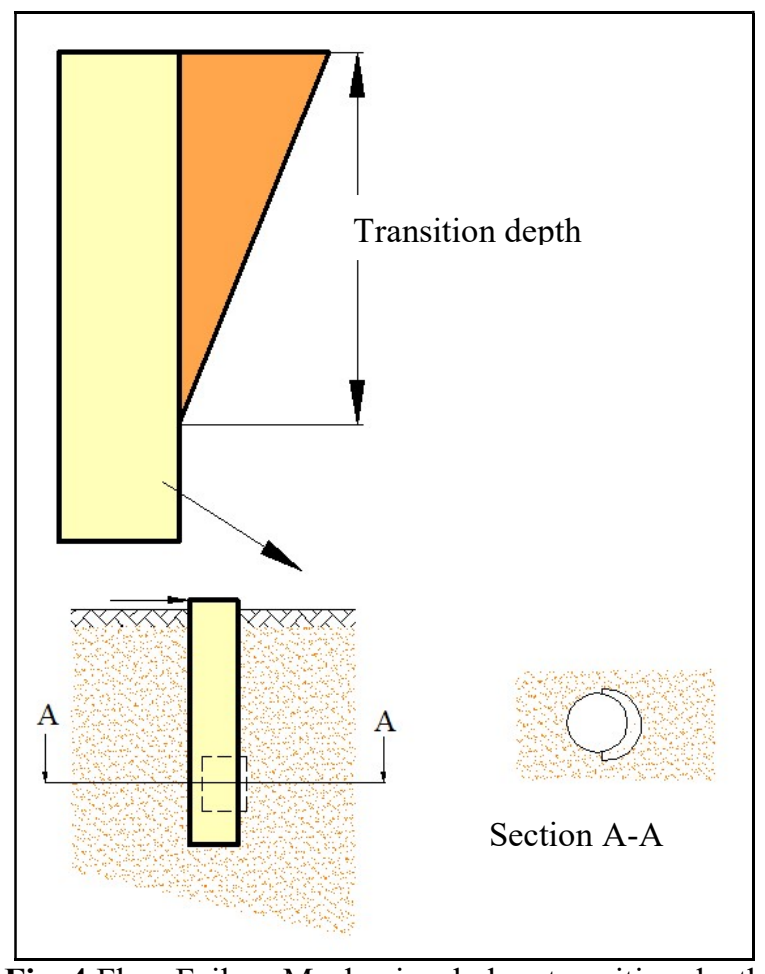

Fig. 4 Flow Failure Mechanism below transition depth

From this point there 1s no 1ncrease in soil resistance whereas strain deformations increase. These $p$-y curves were formulated for jackup-leg piles used in oil and gas industry based on the results from slender and flexible piles. Based on investigations done by Achmus [3], Lesny [20] and Ashford [11] it is found that the initial stiffness is overestimated in conventional p-y method which actually varies according to the pile diameter and depth [12] [17].

Hence the pile deflections are underestimated in the conventional p-y method when used for large diameter monopiles [6]. In the design of substructure for offshore wind turbines monopiles of larger diameter are being used. 
Hence finite element modelling is used extensively in extraction of p-y curves in the recent years [1] [3] [4] [5].

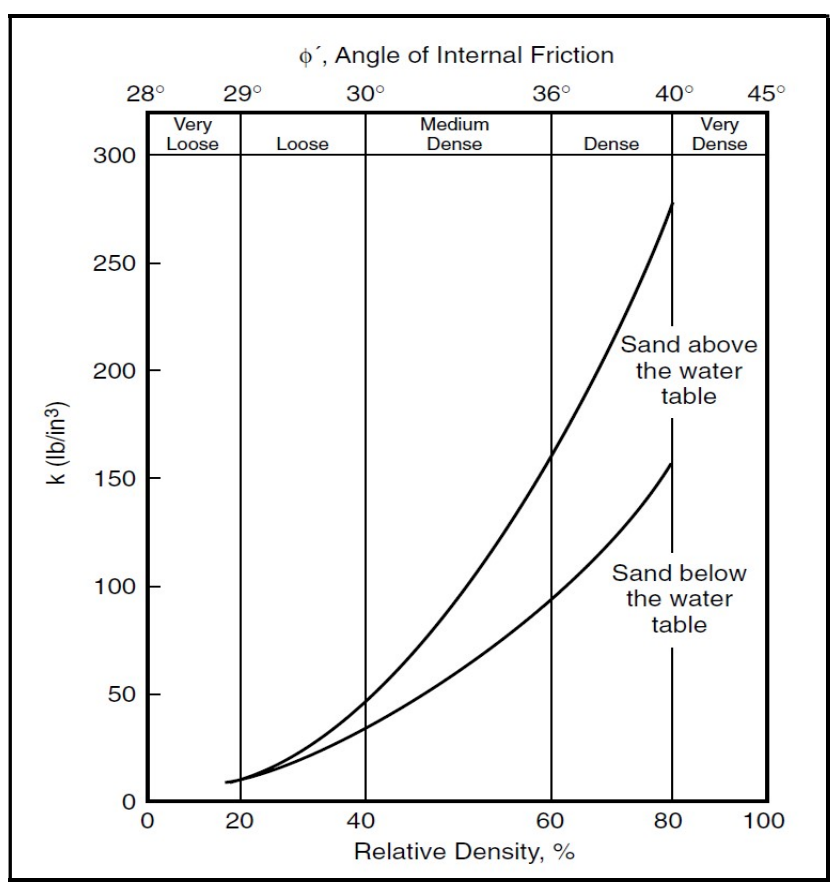

[Reproduced from API RP 2A (2000)]

Fig. 5 Initial subgrade modulus based on angle of internal friction

\section{PILE SOIL INTERACTION- FEM METHOD}

Finite Element modelling of offshore wind turbine monopile is done using Finite Element Modelling tool Plaxis $3 \mathrm{D}[22]$.In this study seven configurations of monopiles with diameter varying from $1 \mathrm{~m}$ to $7 \mathrm{~m}$ are considered. The soil domain around the pile is of five times the diameter(5d) of the pile for each configuration, as the stresses outside this domain are negligible [25].The depth of the domain is considered in such a way that a soil layer of five times the diameter is below the tip of the pile .

The monopile is modelled as hollow cylinder which protrudes $5 \mathrm{~m}$ above the soil layer with an embedment length of about $30 \mathrm{~m}$. The thickness of the pile is considered as per IS 800 to avoid local buckling i.e. Diameter/thickness ratio $<146 \varepsilon^{2}$.A rigid plate is modelled at the top of this pile and loads are applied at the centre of the plate. This protruded system with rigid plate helps in proper transfer of loads to the pile below the seabed and avoids local stress concentration in the required zone.

The soil is modelled using Mohr -Coulomb model [2][9][22] considering sandy soil with angle of internal friction $30^{\circ}$. And the pile is modelled as elasto-plastic material considering properties of $\mathrm{Fe} 250$.

The soil is modelled as 10 -noded tetrahedral elements as show in Fig. 8. The plate elements are modelled as 6-noded triangular elements as shown in Fig. 7.The interface elements between the soil and plate element is meshed as double-noded element as shown in Fig. 9.The distance between the pair of nodes is zero and it is compatible with soil/plate element. These interface elements create the interaction between the soil and structure.

In order to generate the mesh, a global meshing parameter is required which represents target mesh element size, $1_{\mathrm{e}}$. This parameter is calculated from the outer geometry dimensions of the domain such as $\mathrm{X}_{\min }, \mathrm{X}_{\max }, \mathrm{Y}_{\min }, \mathrm{Y}_{\max }, \mathrm{Z}_{\min }$, and $\mathrm{Z}_{\max }$.

$1_{\mathrm{e}}=\mathrm{r}_{\mathrm{e}} \mathrm{x} \sqrt{\left(\mathrm{X}_{\max }-\mathrm{X}_{\min }\right)^{2}+\left(\mathrm{Y}_{\max }-\mathrm{Y}_{\min }\right)^{2}+\left(\mathrm{Z}_{\max }-\mathrm{Z}_{\min }\right)^{2}}$

Where $r_{\mathrm{e}}$ is the relative element size factor which by default taken as a value of 1 . Further mesh can be refined and coarsened globally using this relative element size factor with values varying from 2(very coarse) to 0.5 (very fine).Hence according to the domain chosen for analysis the mesh is generated globally by varying the relative element

As large stress concentration occurs locally around the pile local refinement is done using local fineness factor of 0.5 which reduces the element size to half the target element size.

The initial stresses for calculations are influenced by the weight of the material. The horizontal effective stresses $\left(\sigma_{\mathrm{h}}\right)$ for initial condition are estimated from effective vertical stress $\left(\sigma_{\mathrm{v}}\right)$ considering lateral earth pressure at rest Ko [22].

$$
\sigma_{\mathrm{h}}=\mathrm{K}_{\mathrm{o}} \times \sigma_{\mathrm{v}}
$$

With these initial stresses further calculations are done in the successive steps. In the next step monopile is generated replacing the soil volumes by the plate elements and contact between soil and monopile is being developed

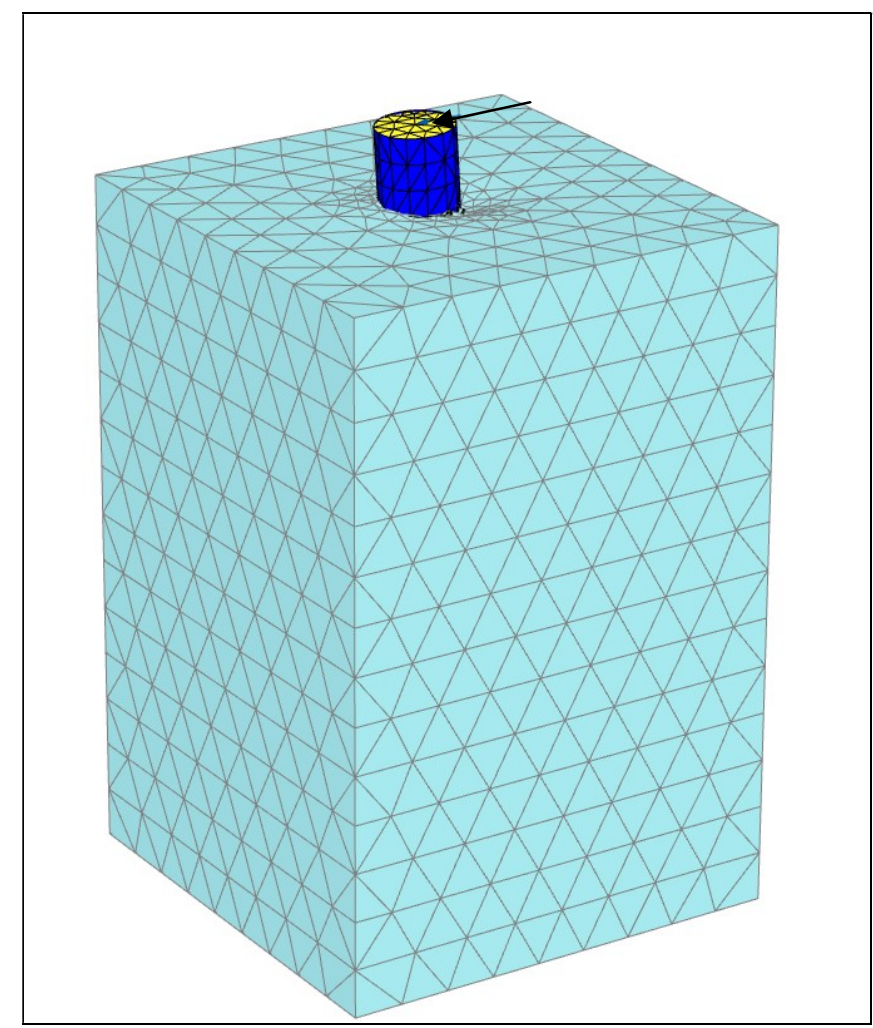

Fig. 6 Finite Element model in Plaxis 3D 


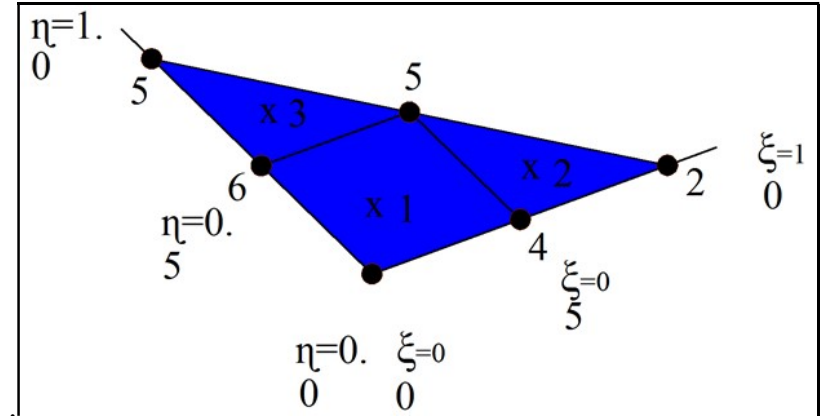

Fig. 7 6-noded plate element

Table 1 Capacity of sections

\begin{tabular}{|l|l|l|l|}
\hline Diameter(m) & Thickness(m) & Length(m) & $\begin{array}{l}\text { Maximum } \\
\text { load } \\
(\mathrm{kN})\end{array}$ \\
\hline 1 & 0.01 & 30 & 300 \\
\hline 2 & 0.02 & 30 & 1100 \\
\hline 3 & 0.03 & 30 & 2200 \\
\hline 4 & 0.04 & 30 & 4600 \\
\hline 5 & 0.05 & 30 & 10000 \\
\hline 6 & 0.06 & 30 & 13000 \\
\hline 7 & 0.07 & 30 & 26000 \\
\hline
\end{tabular}

The maximum load that can be applied at top of pile is estimated for an interaction ratio of 1 as per API standard which is shown in Table. 1 for all configurations. This load is applied in 10 equal increments and the resistance of the soil along with deflections for every one meter strip of soil is arrived.

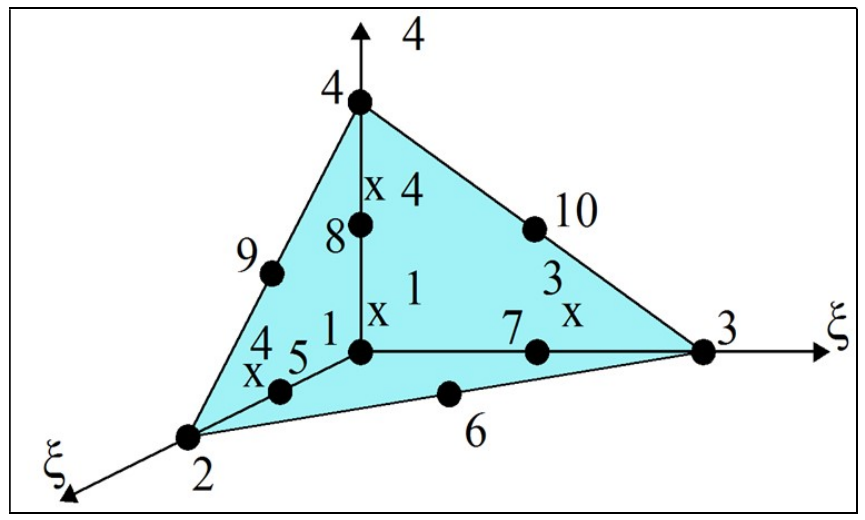

Fig. 8 3D soil elements (10-noded tetrahedrons)

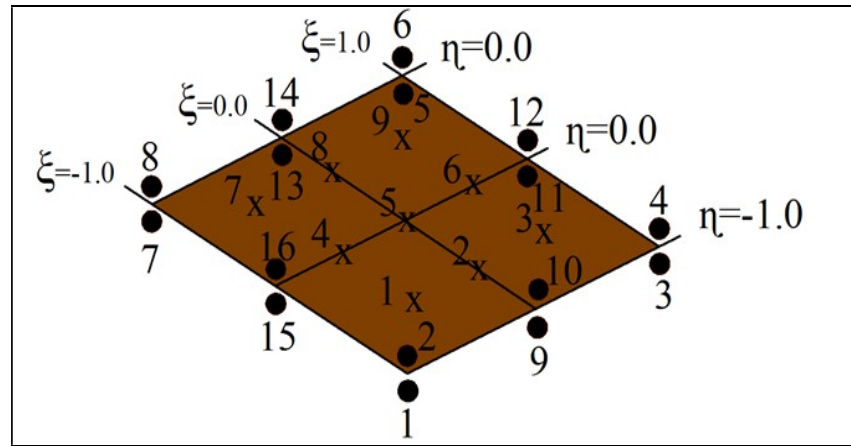

Fig. 9 Interface element with pair of nodes

\subsection{Result Extraction}

From the Finite Element Modelling of Plaxis 3D for all the seven configurations of piles $p$-y curves needs to be extracted. The horizontal loads applied on the model must be in equilibrium with the resistance generated from soil. The horizontal displacement (y) can be determined from the plate element of the FEM model.

The soil resistance (p) due to horizontal loads is extracted from the interface elements around the pile. The interface elements are also modelled every one meter along the depth of pile.

The results from FEM provides the stresses due to applied horizontal load in three components such as

i) The effective normal stress $\left(\sigma_{\mathrm{n}}\right)$

ii) The Horizontal shear stress $\left(\tau_{1}\right)$

iii) The vertical shear stress $\left(\tau_{2}\right)$

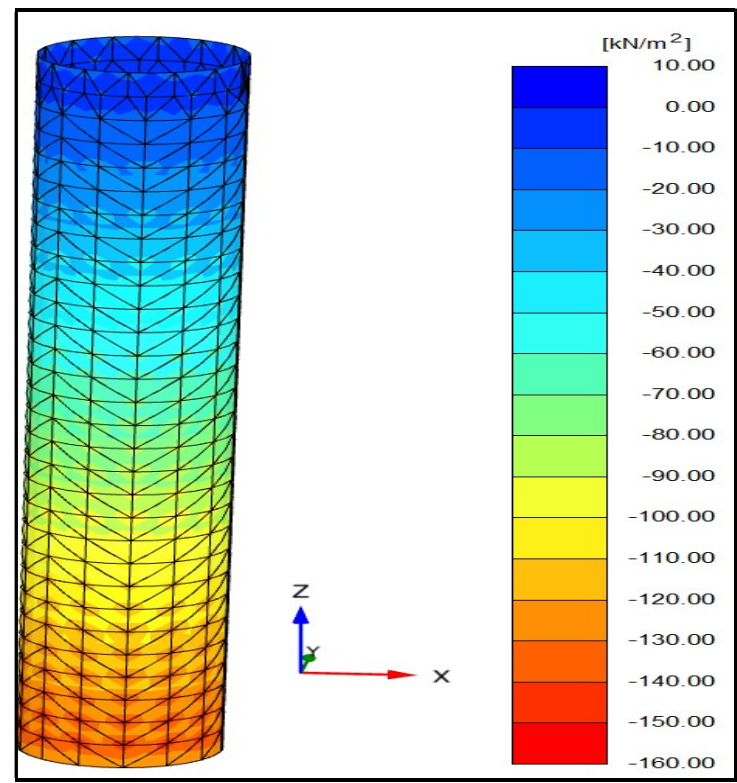

Fig. 10 Effective Normal stress in the interface element

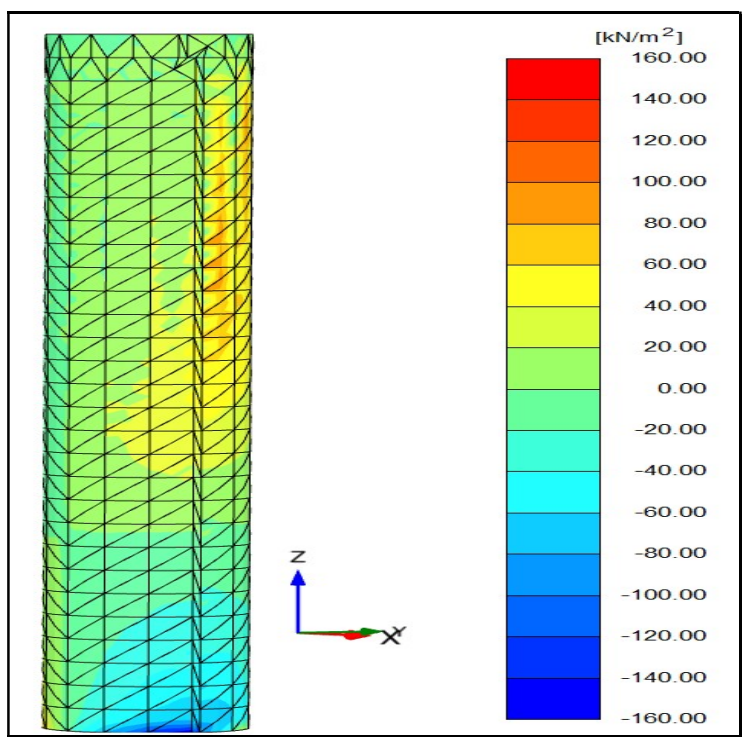

Fig. 11 Horizontal shear stress in interface element 
In order to extract the lateral resistance of the soil only normal stress $\left(\sigma_{\mathrm{n}}\right)$ and horizontal shear stress $\left(\tau_{1}\right)$ need to be considered, as vertical shear stress $\left(\tau_{2}\right)$ should be considered in case of axially loaded condition. Effective normal and horizontal stresses are shown in Fig.10 and Fig. 11. The soil resistance $(\mathrm{p})$ is generated in the direction opposite to the lateral loads.

The stress values are extracted from the stress points of the interface elements for every individual load increment separately. The stress in every individual interface element is shown in Fig. 12.

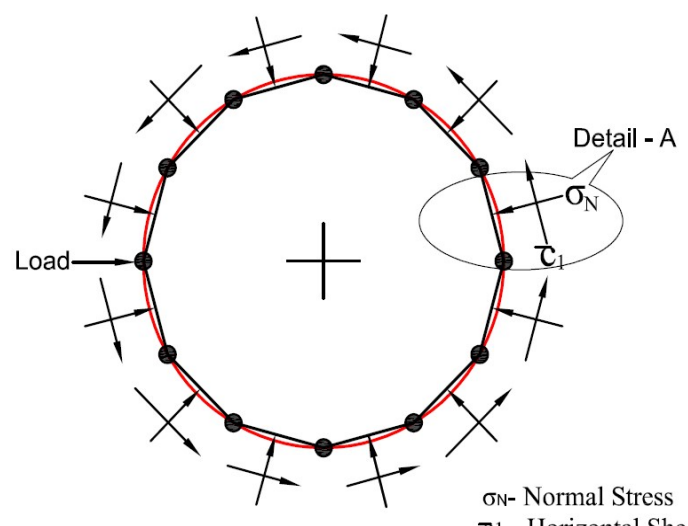

Top View of Interface c1 - Horizontal Shear Stress

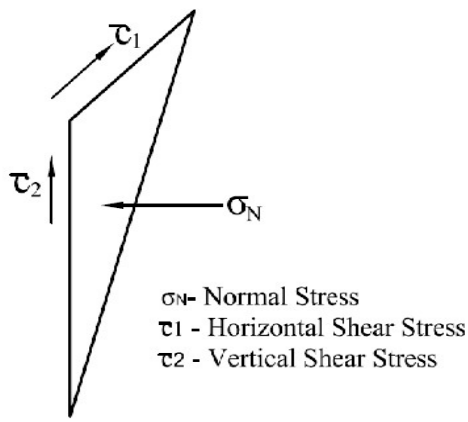

Mesh Element with

stresses from Soil Detail - A

Fig. 12 Interface elements with stresses

The stress value of the corresponding load step in every interface element is obtained by subtracting the stresses developed in the initial step of that interface element.

\footnotetext{
$\sigma_{\mathrm{n}}=\sigma_{\mathrm{n}(\text { corresponding load step)- }} \sigma_{\mathrm{n}((\text { Initial step })}$

$\tau_{1}=\tau_{1 \text { (corresponding load step) - }} \tau_{1(\text { Initial step) }}$
}

The interface elements are numerically integrated using Gaussian Integration points. The stresses obtained from six stress points of every interface element and multiplied with a weightage factor of $\mathrm{W}_{\mathrm{f}}$.

$$
\begin{aligned}
& \sigma_{\mathrm{n}(\mathrm{final}}=\left(\sigma_{\mathrm{n}(1)}+\sigma_{\mathrm{n}(2)}+\sigma_{\mathrm{n}(3)}+\sigma_{\mathrm{n}(4)}+\sigma_{\mathrm{n}(5)}+\sigma_{\mathrm{n}(6)}\right) \times \mathrm{W}_{\mathrm{f}} \\
& \tau_{1(\text { final })}=\left(\tau 1_{(1)}+\tau_{1(2)}+\tau_{1((3)}+\tau_{1(4)}+\tau_{1(5)}+\tau_{1(\text { (6) }}\right) \times \mathrm{W}_{\mathrm{f}}
\end{aligned}
$$

Where $\sigma_{\mathrm{n} \text { (final) \& }} \tau_{1 \text { (final) }}$ are the final stress obtained in every individual interface element. The normal and the horizontal shear stresses in every individual interface element are resolved in the direction corresponding to that of the applied load with respect to the centre of gravity of the interface element.

Stress (every element) $=\sigma_{n(\text { final) (horizontal comp) }}+\tau_{1}$ (final)(horizontal comp)

This is the stress developed in every individual interface element. The area of the triangular interface element is found by considering the curvature effects. The interface element with curvature effect is shown in Fig. 13

The curved length $(R \theta)$ of the interface element is found with respect to the centre of pile $(\mathrm{O})$ and chord length $(\mathrm{C})$ which is distance between the nodes on the triangular element at same level as shown in Fig. 13.

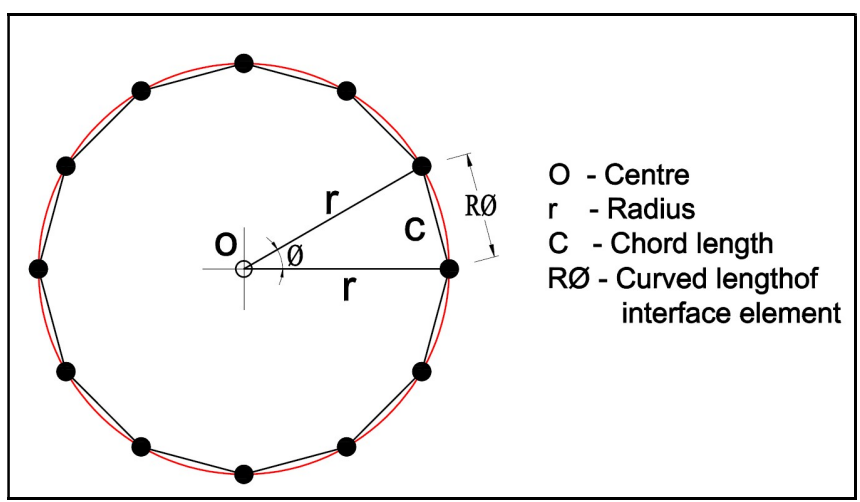

Fig. 13 Interface element with curvature effect

The curved length of the interface element:

$\mathrm{R} \theta=2 \operatorname{Sine}^{-1} \frac{C}{2 R}$

Where $\mathrm{R}$ is the radius of the pile as shown in Fig. 13.The area of every individual interface element

$A_{(\text {every element) }=}=1 / 2 \times R \theta \times$ Height of the interface element

The calculated area of the every individual interface element is multiplied with the stress obtained for the individual interface element to get the resistance in every individual interface.

$$
\text { Resistance }_{\text {(every element) }}=\text { Stress }_{(\text {every element) }} \mathrm{X} \mathrm{A_{ \text {(everyelement) } }}
$$

Similar extraction of resistance is done for all the interface elements for every one meter. The summation of this resistance provides the total resistance (p) for every one meter strip of pile along the depth.

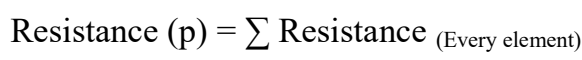




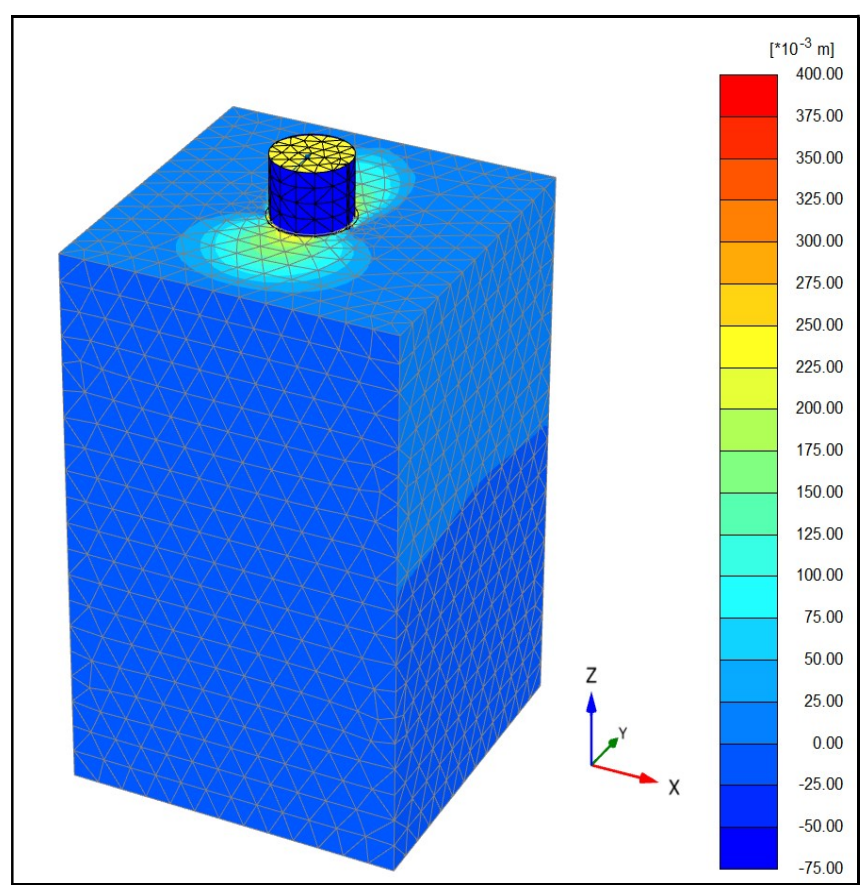

Fig. 14 Deflection contour in the lateral direction

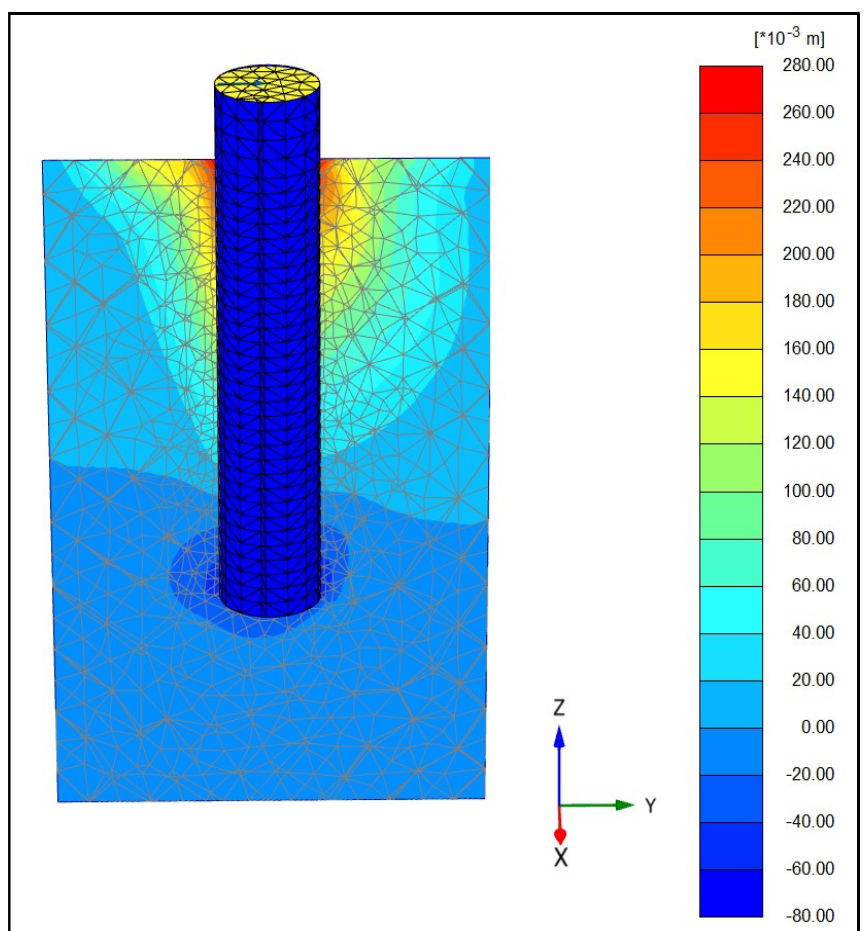

Fig. 15 Lateral deflection contour in vertical cross section

Similarly the lateral deflection (y) is also extracted for every one meter depth of the pile. The deflection contour is shown in Fig.14. With these $p$ and y values $p$-y curves for every one meter depth is obtained . Similar extraction procedure of p-y curves is done for all the seven configuration of pile. The vertical and lateral cross section for the deflection contour is shown in Fi.g.16 and Fig.17.

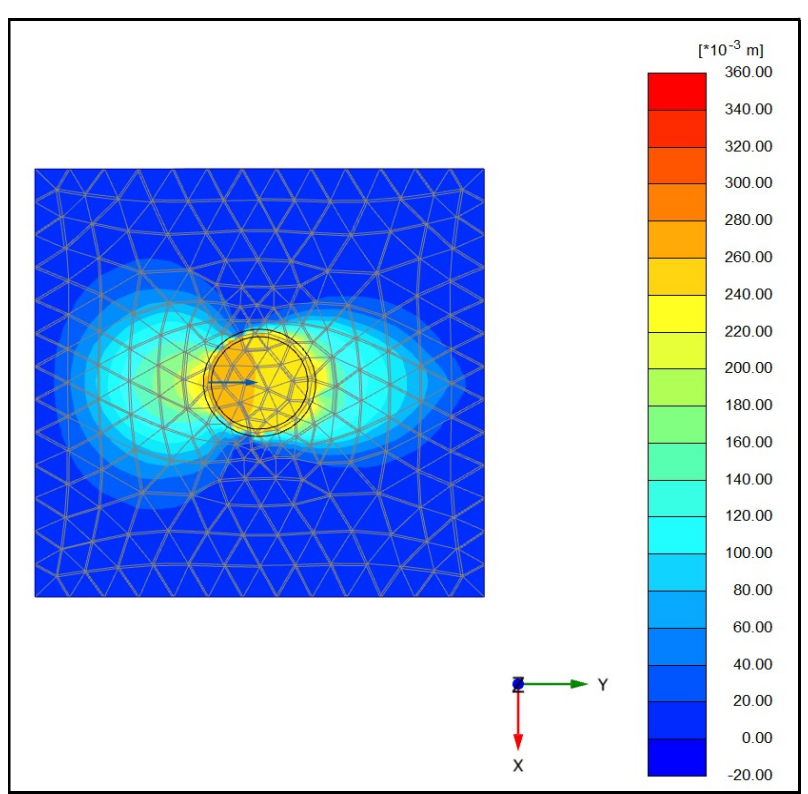

Fig. 16 Lateral deflection contour in horizontal cross section

\subsection{Equilibrium Check}

The total soil resistance obtained along the entire depth of pile should be in equilibrium with the horizontal load applied at the top of the pile.

The soil resistance is obtained as described above for all the load increments. The soil resistance obtained should be the same as that of the load applied but in opposite sign. Then the pile soil system is set to be in equilibrium.

Equilibrium check is done for all the configurations .A sample calculation of equilibrium check for $1 \mathrm{~m}$ diameter pile is shown in

Table 2. In this configuration $300 \mathrm{kN}$ is the maximum load to be applied as shown Table 1le 1 which is applied as 10 increments \& equilibrium is checked for all loads.

Table 2 Equilibrium check for $1 \mathrm{~m}$ diameter monopile

\begin{tabular}{|l|l|l|l|}
\hline S.NO & Load $(\mathbf{k N})$ & Resistance( $\mathbf{k N})$ & \% of error \\
\hline 1 & 30 & -029.74 & 0.86 \\
\hline 2 & 60 & -059.93 & 0.17 \\
\hline 3 & 90 & -090.63 & 0.70 \\
\hline 4 & 120 & -121.20 & 0.98 \\
\hline 5 & 150 & -151.38 & 0.92 \\
\hline 6 & 180 & -181.21 & 0.67 \\
\hline 7 & 210 & -210.60 & 0.28 \\
\hline 8 & 240 & -240.15 & 0.06 \\
\hline 9 & 270 & -269.90 & 0.03 \\
\hline 10 & 300 & -299.32 & 0.23 \\
\hline
\end{tabular}

It is found that the maximum error between the extracted horizontal soil resistance and the applied horizontal load among all load steps is less than $1 \%$, as the Finite Element modelling generally solves any calculation with some tolerated error. Similarly the maximum error tolerance check is done for all the seven configurations. It is found that in all configurations the error is negligible. 


\section{P-Y CURVES-API METHOD}

For the same seven configurations, $\mathrm{p}$-y curves are obtained using the conventional API method. The soil resistance (p) for every one meter soil layer is obtained as per API RP2A for the same set of deflections (y) with which p-y curves are obtained from FEM method. The API p-y curves obtained for all the seven configurations are shown respectively in Fig. 17 to Fig. 23. These p-y curves are extracted for all the layers throughout the depth of the pile whereas the top six layers are shown in Fig. 17- Fig. 23 as the resistance in the top layers of soil play a significant role in pile design.

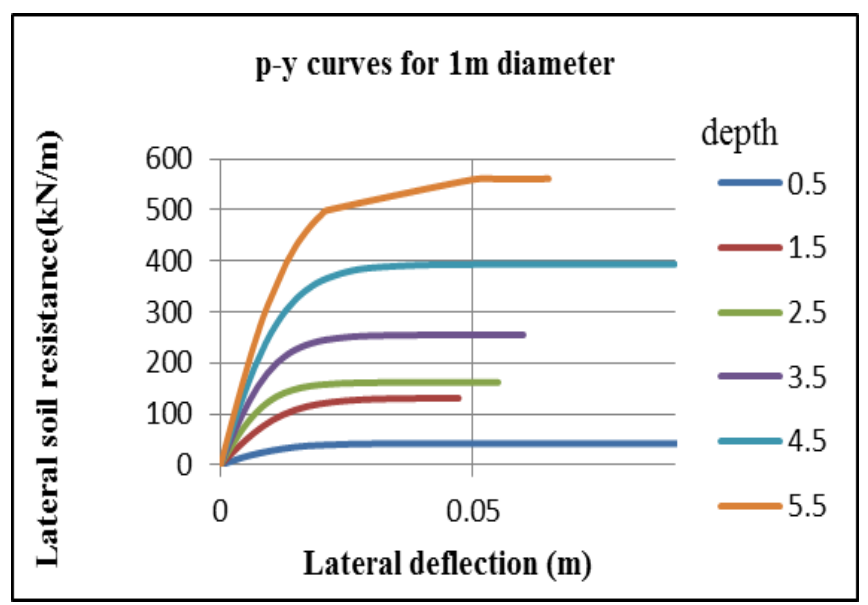

Fig. 17 p-y curves for $1 \mathrm{~m}$ diameter pile in sand

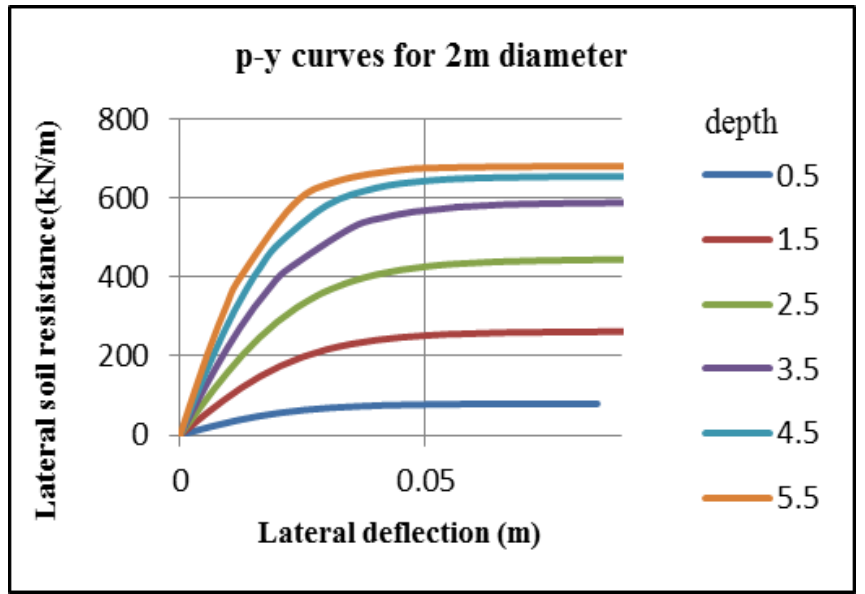

Fig. 18 p-y Curves for $2 \mathrm{~m}$ diameter pile in sand

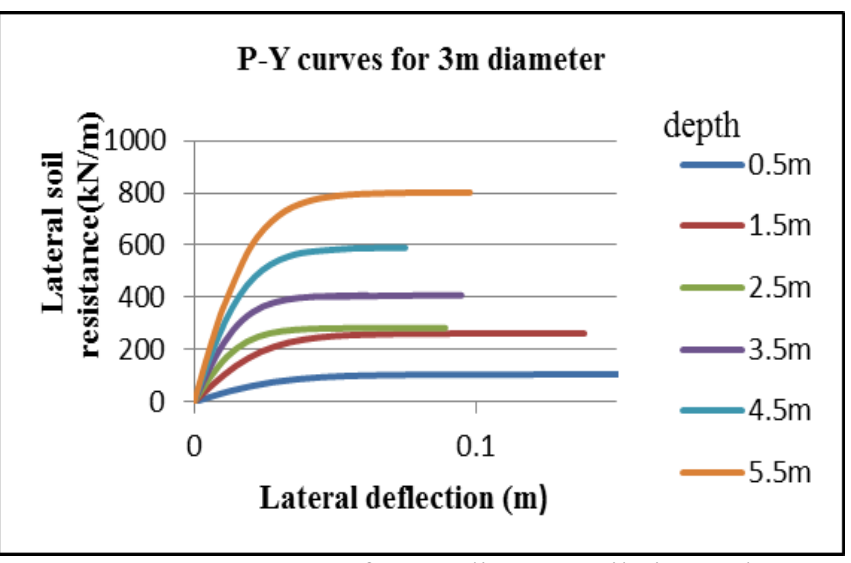

Fig. 19 p-y Curves for $3 \mathrm{~m}$ diameter pile in sand

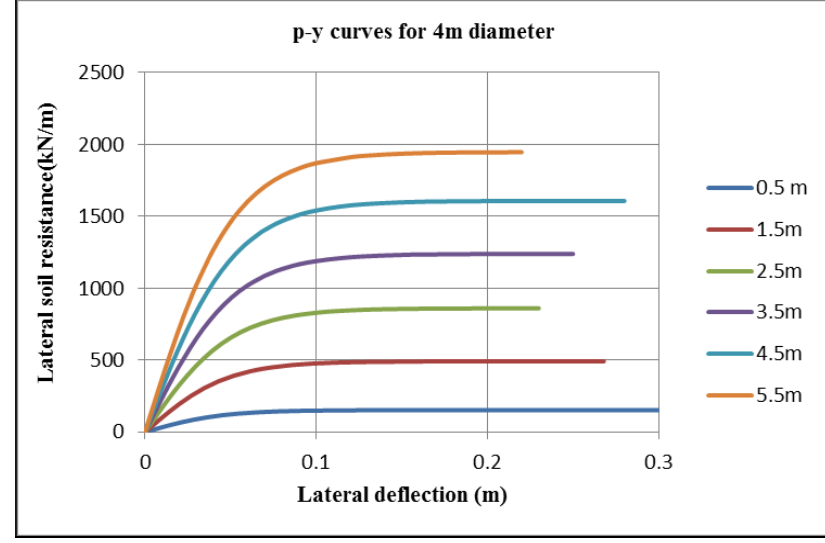

Fig. $20 \mathrm{p}$-y curves for $4 \mathrm{~m}$ diameter pile in sand

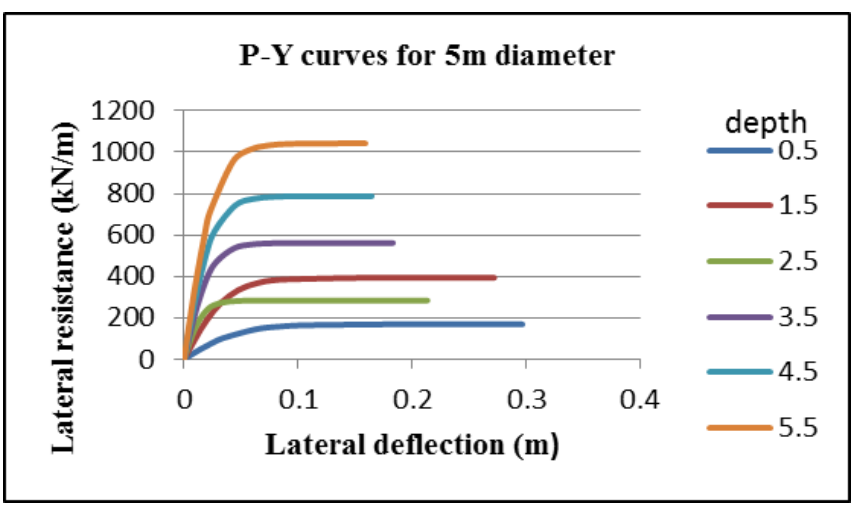

Fig. 21 p-y curves for $5 \mathrm{~m}$ diameter pile in sand

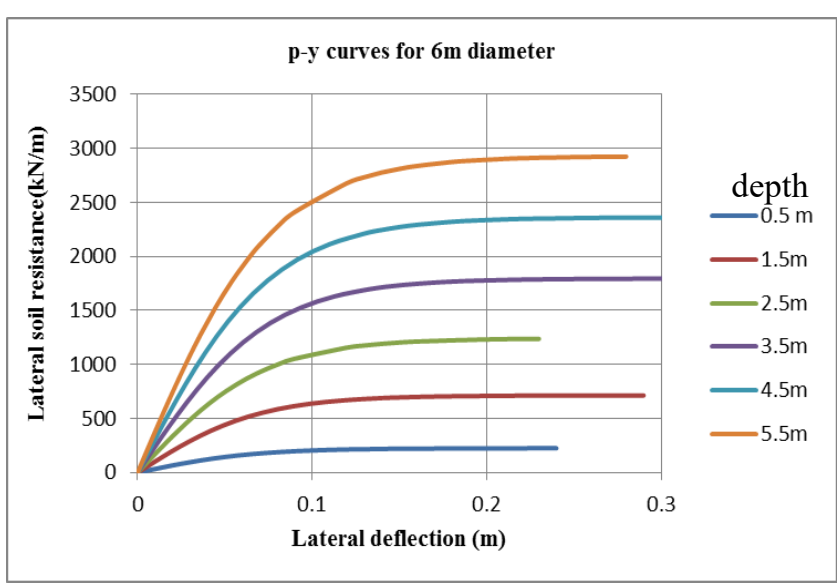

Fig. $22 \mathrm{p}$-y curves for $6 \mathrm{~m}$ diameter pile in sand

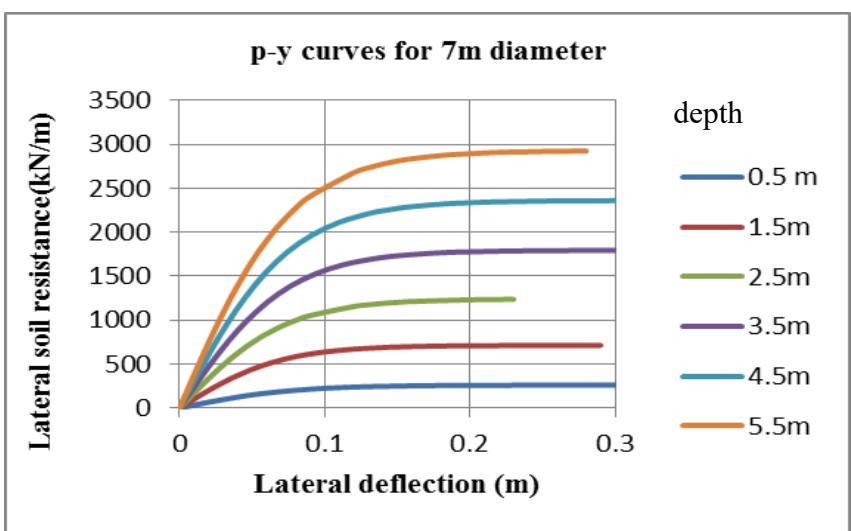

Fig. $23 \mathrm{p}$-y curves for $7 \mathrm{~m}$ diameter pile in sand 


\section{RESULTS AND DISCUSSION}

With the soil resistance (p) and the deflection (y) obtained the $p-y$ curves are formulated with the soil resistance (p) along the $\mathrm{y}$-axis and the lateral deflection(y) along the $\mathrm{x}$-axis using both FEM method and API method.

It is observed that the curves from both the FEM and API methods corresponds each other for diameters up to $2 \mathrm{~m}$ as shown in Fig.24.

It is found that the p-y curves extracted from FEM and API method does not correspond each other for diameter greater than $2 \mathrm{~m}$. It is also observed that $\mathrm{p}$-y curves generated by both the methods starts deviating from each other from $3 \mathrm{~m}$ diameter of pile showing larger variation in case of larger diameter of pile as shown in Fig. 25 - Fig.28

This is because in p-y method, the factor $\mathrm{k}$ is independent of the pile diameter whereas in FEM the initial stiffness is varied according to the pile diameter. It is small for smaller diameter and large for larger diameter. Hence the soil modelled with API method behaves stiffer than the soil modelled with FEM irrespective of the diameter of the pile. It is due to this fact that the p-y curves obtained in case of larger diameter pile from FEM are higher compared to the API method.

In case of larger diameter monopiles the bottom tip of the pile has a rotation and horizontal displacement which generates additional forces in the pile. Hence the pile has more resistance in the soil. This effect is also considered in FEM method but it is not considered in API method

And also in larger diameter monopile more rotation is found all along the length of the pile.
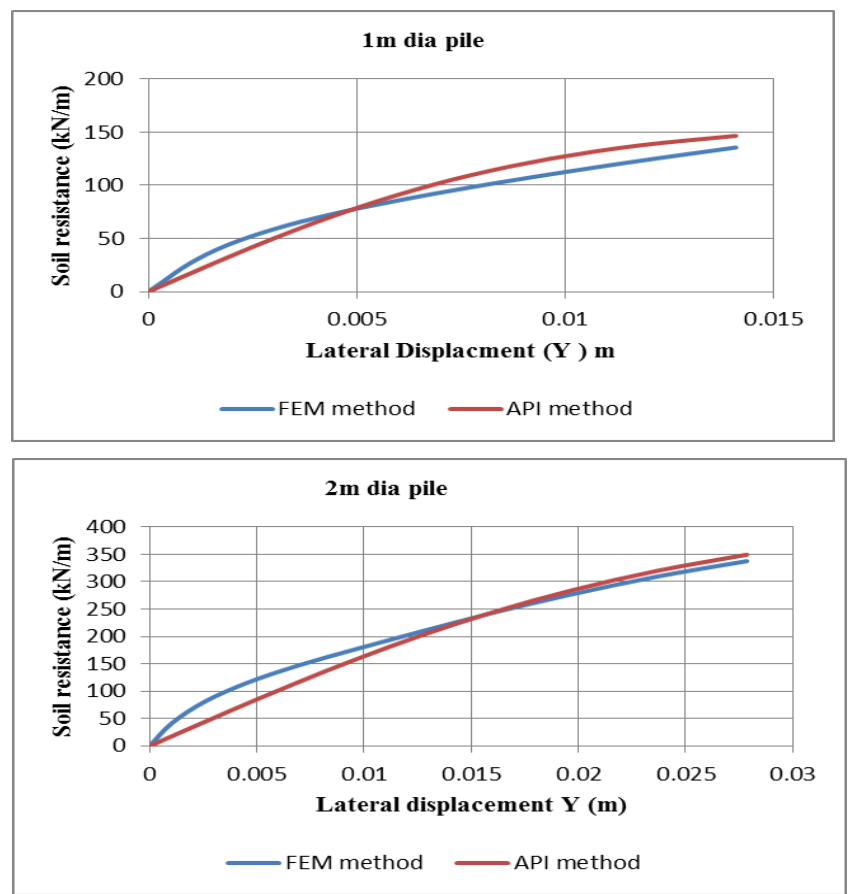

Fig. 24 P-Y curves from FEM and API method for 1m, $2 \mathrm{~m}$ diameter of monopiles.
This also creates additional vertical stresses along the depth of the pile which creates more resistance of the pile in the soil. This effect is also not considered in API method.

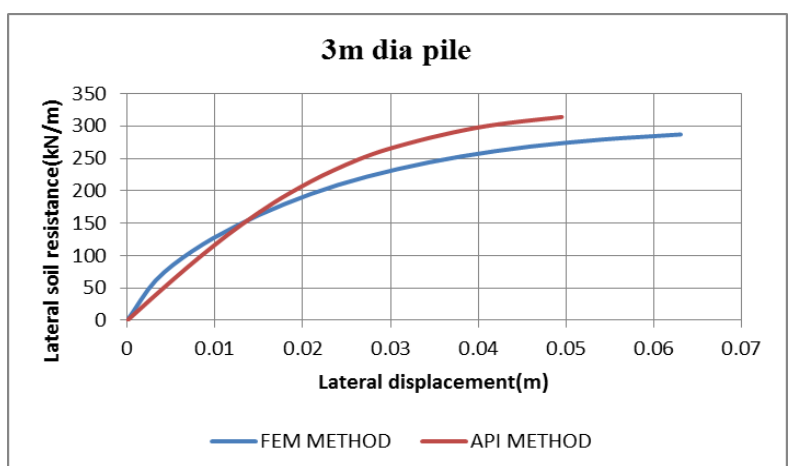

Fig. 25 P-Y curves from FEM and API method for $3 \mathrm{~m}$ diameter monopile

The percentage of difference in pile tip deflection for various diameters of monopile is shown in Fig. 27, it is also observed that the pile tip deflection obtained from FEM method and conventional API method corresponds each other for smaller diameter piles.

In the case of larger diameter $(>2 \mathrm{~m})$ piles the percentage difference in pile tip deflection between API and FEM method increases as diameter of the pile increases from $20 \%$ to $50 \%$. As the deflections generated from FEM method are larger for large diameter of pile, the stresses will also be larger for larger diameter. Hence the stresses are underestimated in API method.

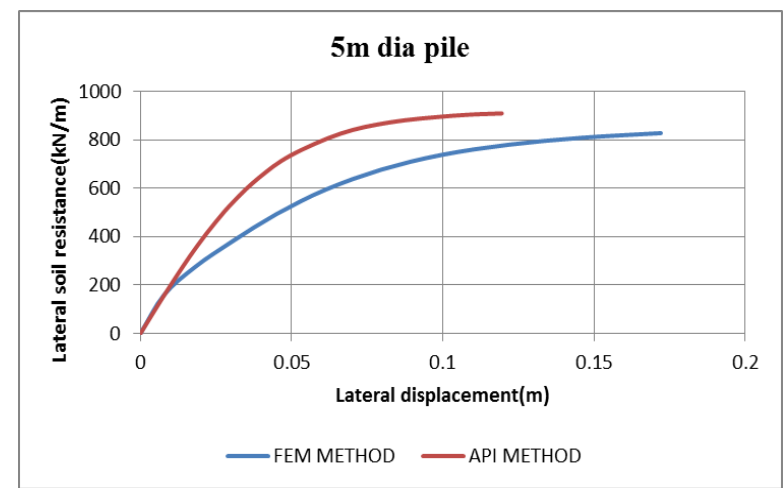

Fig. 26 P-Y curves from FEM and API method for 5m diameter of monopiles.

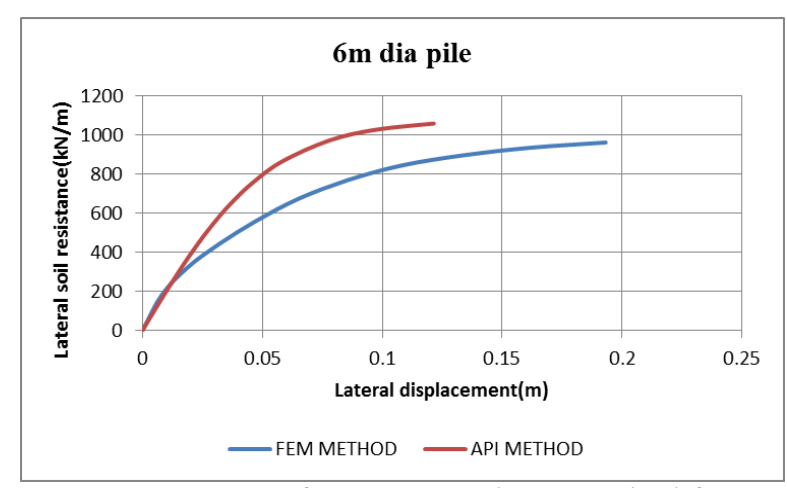

Fig. 27 P-Y curves from FEM and API method for $6 \mathrm{~m}$ diameter monopile 


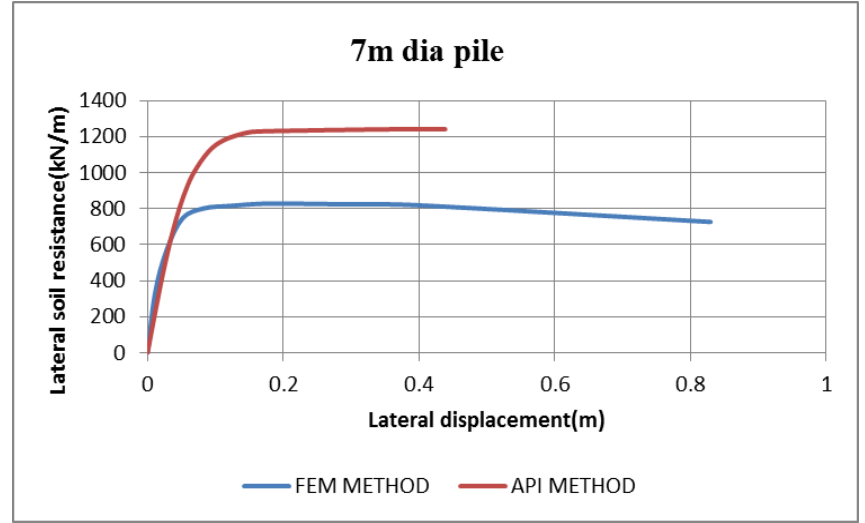

Fig. 28 P-Y curves from FEM and API method $7 \mathrm{~m}$ diameter of monopiles

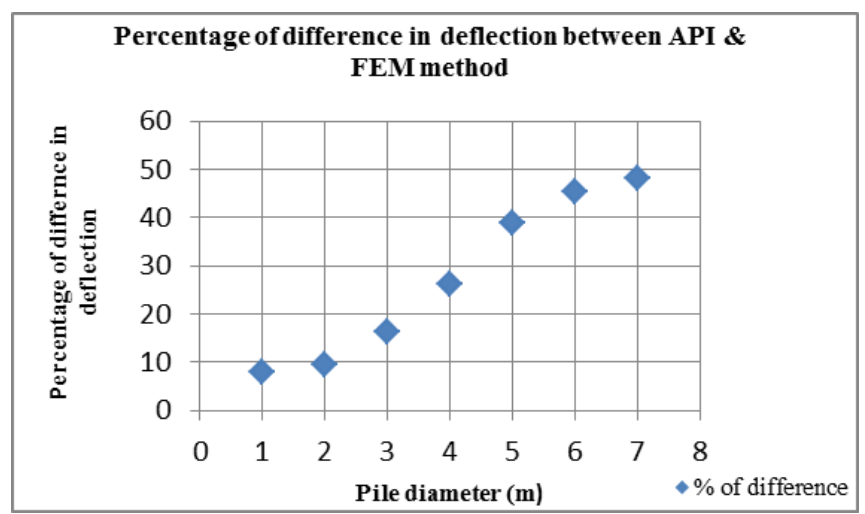

Fig. 27 Percentage of difference in pile tip deflection between API and FEM method

\section{USE OF P-Y CURVES FROM FEM}

In order to perform the total structural system analysis, the nonlinear effects from foundation along with superstructure need to be analysed for various other environmental conditions. A Finite Element model (Model A) is being developed in plaxis for monotonic loading condition for $4 \mathrm{~m}$ diameter pile. Another model (Model B) is being developed in conventional structural analysis software with p-y curves extracted from FEM for exact loading conditions. Pile tip deflections from both models are being studied. It is found that the pile tip deflection from Model B corresponds with the pile tip deflection of Model A. Hence p-y curves generated from FEM can be used in conventional structural analysis so that it can be used for other special type of analysis such as time history wave and wind. Tip deflection Comparison for $4 \mathrm{~m}$ diameter pile is shown in Table 3.

Table 3 Comparison of Pile Tip Deflection

\begin{tabular}{|l|l|l|}
\hline S.no & Type of Model & Deflection(mm) \\
\hline 1 & Model A & 50 \\
\hline 2 & Model B & 48 \\
\hline
\end{tabular}

\section{CONCLUSION}

It is found that FEM model set up with the specifications explained earlier can be used in extraction of the $\mathrm{p}-\mathrm{y}$ curves for every one meter along the depth of the pile.
It is observed that the horizontal soil resistance (p) obtained is in equilibrium with the horizontal load applied for every load step increment in all the configurations of the pile.

It is found that p-y curves extracted from FEM in case of smaller diameter $(<2 \mathrm{~m}$ dia) monopile corresponds with the curves extracted from conventional API method whereas in case of the larger diameter monopile the curves from both the methods does not corresponds each other .

The reason for the difference in curves is due to the stiffness assumption in both the methods varies. In case of API method the stiffness of the soil is overestimated whereas in FEM it varies according to the diameter.

Is also concluded that the tip displacements obtained from FEM are larger than the conventional API method. This is due to the fact that the large diameter piles provide larger resistance to the soil due to the increased surface area. Hence the soil resistance decreases leading to increased deflection. Hence in case of large diameter the pile behaves more rigid. These diameter effects are not considered in API method.

It is also concluded that the p-y curves extracted from FEM can be used in conventional structural analysis software for other special type of analysis in order to simulate the original site conditions.

Hence it is concluded that in the design of larger diameter monopile $(>2 \mathrm{~m})$ for offshore wind turbine it is more suitable to set up Finite Element modelling in order to generate the p-y curves as the API method underestimates the stresses and deflections.

\section{ACKNOWLEDGEMENT}

The authors wish to express their sincere thanks to Dr. M.A. Atmanand, Director, NIOT, for his keen interest and encouragement. The authors thankfully acknowledge the support extended by MoES in funding the project.

\section{REFERENCES}

[1]. Abdel-Rahman, K., Achmus, M., "Finite element modelling of horizontally loaded Monopile Foundations for offshore wind Energy Converters in Germany", Institute of soil mechanics, Foundation engineering and water power engineering, University of Hannover,Germany.

[2]. Abbo, A.J., Lyamin. A.V., Sloan, S.W., Hambleton, J.P., " A C2 continuous approximation to the MohrCoulomb yield surface" , International journal of Soilds and Structures, Vol 48,pp 3001-3010,2011.

[3]. Achmus, M, "Design of axially and laterally loaded Piles for the support of Offshore Wind Energy Converters", Indian Geotechnical Conference-2010

[4]. Achmus, M., Abdel-Rahman, K., Kuo,Y.S., "Behavior of large diameter monopiles under cyclic horizontal loading", Proceedings of the $12^{\text {th }}$ ICSGE,CairoEgypt,Dec 2007. 
[5]. Achmus, M., Abdel-Rahman, K., Kuo ,Y.S., "Numerical Modelling of large diameter steel piles under monotonic and cyclic horizontal loading", Proceedings of the $10^{\text {th }}$ international symposium on numerical models in geomechanics, pp. 453-459, Rhodos, Greece,April 2007.

[6]. Achmus, M., Albeizer, J., Peralta,P., Tom Warden, F., "Scale effects in design of larger diameter monopiles", Proceedings of the $11^{\text {th }}$ EWEA, 2011.

[7]. Amar Bouzid, Dj., Bhattacharya, S., Dash, S.R., “ Winkler springs for pile design from stress-strain of soils:FE assessment of scaling coefficients using the mobilized strength design concept", Geomechanics and Engineering, Vol. 5,No. 5,pp 379-399,2013.

[8]. American Petroleum Institute (API), "Recommended Practice for Planning, Designing and Construction Fixed Offshore Platforms-Working stress Design “, API recommended practice 2A-WSD (RP 2A-WSD), Washington D.C., 12th Edition, December 2000.

[9]. Amr Farouk Elhakim,Mohamed Abd Allah El Khouly,Ramy Awad, "Three dimensional modelling of laterally loaded pile groups resting in sand" , HBRC Journal,2014.

[10]. Arunjyoti Sarkar, Guested, ove.T., "Study on new method for installing a monopile and a fully integrated offshore wind turbine structure", Marine structures, Vol. 33,PP 160-187,2013.

[11]. Ashford, S.A., Juirnarongrit, T., "Evaluation of Pile Diameter Effect on Initial Subgrade Modulus of Subgrade Reaction “, Journal of Geotechnical and geoenvironmental engineering, ASCE, March 2003.

[12]. Augustesen, A.H., Broadbaek, K.T., Moller, M., Sorensen, S.P.H., Ibsen, T.S., Andersen, L., "Numerical modelling of Large diameter steel piles at Horns Rev", Proceedings of the $12^{\text {th }}$ International congress on civil,structural and Environmental Engineering computing,Scotland,2009.

[13]. Bernd, M., Lixuan, H., Reinhard, L., Frede, H., (2012), "Evaluation of offshore wind resources by scale of development", Energy 48, pp 314-322.

[14]. Butterfield CP, Musial W, Jonkman J., "Overview of offshore wind technology":preprint. In: Proceedings of Chinese renewable energy industry association conference, Shanghai, China; 2007

[15]. Det Norske Veritas (DNV), "Design of offshore wind Turbine Structures", offshore standard DNV-OS-J101, Norway, June 2004.

[16]. Durba Lal Pradhan, "Development of P-Y curves for Monopiles in clay using Finite Element model Plaxis 3D", Norwegian university of science and technology, 2012.

[17]. Ignatius P.O. Lam, "Diameter effects on p-y curves", Earth mechanics, CA, USA.

[18]. IS 800 Part -3, (2007) "General construction in steel code of practise".

[19]. Joseph Appiott,Amardeep Dhanju,Biliana CicinSain,"Encouraging Rewable energy in offshore Environment", Ocean and coastal management,vol 90,pp5864,2014 .

[20]. Lesny, K. Paikowsky, S.G, Gurbuz.A, "Scale effects in lateral load response of larger diameter monopiles", GeoDenver 2007, Denver, USA.
[21]. Perez-Collazo.C., Greaves.D., Iglesias.G., “ A review of combined wave and offshore wind energy", Renewable and sustainable energy reviews, vol 42,PP 141-153,2014.

[22]. Plaxis 3D, Material models manual, version 2.

[23]. Schaumann, P.; Böker, C., "Can Tripods and Jackets compete with Monopiles?" Contribution to Copenhagen Offshore Wind, 26-28 October '05.

[24]. Seidel, M., "Feasibility of monopiles for large offshore wind turbine", in: Proceedings of the $10 \mathrm{~h}$ German wind energy conference [DEWEK]., Bremen, Germany; 2010.

[25]. Shamsher Prakash, Hari D.Sharma,"Pile Foundations in engineering Practice", Wiley Interscience publication,pp 27-28.

[26]. Wystan Carswell, Sanjay Raja Arwade, Don J.DeRoot, Matthew A.Lackner, "Soil structure reliability of offshore wind Turbine monopile foundations", Wind Energy 2014. 